\title{
Randomizowane badania kliniczne w protonoterapii- jedyna słuszna droga?
}

\author{
Randomized Controlled Trials \\ in Proton Beam Radiotherapy - is this the only way?
}

\author{
Marek Konkol ${ }^{1,2}$ \\ ${ }^{1}$ Oddziat Radioterapii I, Wielkopolskie Centrum Onkologii im M. Skłodowskiej-Curie w Poznaniu \\ ${ }^{2}$ Katedra i Zakład Elektroradiologii, Uniwersytet Medyczny im. K. Marcinkowskiego w Poznaniu
}

\section{Streszczenie}

Protonoterapia jest szybko rozwijającą się nową technologią radioterapii onkologicznej. W aktualnej debacie podkreśla się brak wystarczającej ilości randomizowanych badań klinicznych (RCTs, randomizedcontrolledtrials) do udowodnienia jej klinicznej wyższości. Ta praca podsumowuje bieżący stan wiedzy oraz polemizuje z koniecznością używania RCTs do oceny protonoterapii.

\begin{abstract}
Proton Beam Radiotherapy is anemerging new technology in radiation oncology. The current debate underlines the lack of adequate number of randomized clinical trials (RCTs) to prove its clinical priority. This papersums up the present state-of-art and disputes with the need of using RCTs in the assessment of proton therapy.
\end{abstract}

Stowa kluczowe: protonoterapia, radioterapia protonowa, randomizowane badania kliniczne

Keywords: protontherapy, proton beamradiotherapy, randomizedcontrolledtrials

Adres do korespondencji

Marek Konkol

Oddział Radioterapii I,

Wielkopolskie Centrum Onkologii, ul. Garbary 15, 61-866 Poznań, Polska

Telefon. +48618850867

e-mail: marek.konkol@wco.pl 


\section{Wstęp}

Zastosowanie medyczne promieniowania cząsteczkowego i bezsprzeczne korzyści dozymetryczne z jego zastosowania znane są od dekad. Jednak dopiero postęp technologiczny ostatnich lat i istotny spadek cen przyczynił się do intensywnego rozwoju tej metody leczenia. Dzisiaj protonoterapia jest metodą stosowaną na całym świecie-opierając się na danychThe ParticleTherapy Co-OperativeGroup (PTCOG),w kwietniu 2019 roku działało 81 centrów protonoterapii, ado końca 2017w tychże centrachnapromieniono ponad170 o0o pacjentów [1]. Według stanowiska Niemieckiego Towarzystwa Radioterapii Onkologicznej protonoterapia „nie jest terapią eksperymentalną, może być stosowana w oparciu o standardy klasycznej radioterapii i nie wymaga specjalnych zgód przy ich spełnieniu” [2]. Tym niemniej, jak każda kosztowna technologia medyczna, budzi kontrowersje, szczególnie w zakresie efektywności kosztowej.

\section{Randomizowano badania kliniczne w radioterapii cząsteczkowej}

Największym zarzutem wobec radioterapii cząsteczkowej jest niewielka ilość randomizowanych badań klinicznych (RCTs - RandomizedControlledTrials), a więc badań najwyższej mocy udowadniających bezsprzeczną korzyść kliniczną nad klasyczną radioterapią fotonową. Aktualnie w bazie clinicaltrials.gov zarejestrowanych jest 86 aktywnych, rekrutującychinterwencyjnychbadań klinicznych z użyciem radioterapii cząsteczkowej.Spośród nich jedynie 20 zaprojektowanych jest w formie badań randomizowanych (tabela 1.). Warto również zauważyć, że tylko 11 dotyczy bezpośredniego porównania radioterapii fotonowej i protonowej. Wydaje się więc, że sytuacja nie ulegnie zmianie szybko.

tabela 1. Przegląd aktualnie toczących się, aktywnych, rekrutujących randomizowanych badań z użyciem protonoterapii (wg bazy clinicaltrials.gov)

PBT - proton beamradiotherapy, EBRT- externalbeam [photon] radiotherapy

RFA - radio frequency ablation, Carbon - Carbon Ion beam radiotherapy,

CRTH - chemioradioterapia, SBRT - stereotactic body radiotherapy

\begin{tabular}{|c|c|c|c|c|}
\hline Nr NCT & Nazwa & Rozpoznanie & Projekt badania & $\begin{array}{l}\text { Pierwszorzędowy } \\
\text { punk końcowy }\end{array}$ \\
\hline NCTo2603341 & $\begin{array}{l}\text { Pragmatic } \\
\text { Randomized Trial } \\
\text { of Proton vs. Photon } \\
\text { Therapy for Patients } \\
\text { With Non-Metastatic } \\
\text { Breast Cancer: } \\
\text { A Radiotherapy } \\
\text { Comparative } \\
\text { Effectiveness } \\
\text { (RADCOMP) } \\
\text { Consortium Trial }\end{array}$ & Rakpiersi & PBT vs EBRT & $\begin{array}{c}\text { Toksyczność sercowo- } \\
\text { naczyniowa }\end{array}$ \\
\hline NCTo3186898 & $\begin{array}{l}\text { Radiation Therapy } \\
\text { With Protons or } \\
\text { Photons in Treating } \\
\text { Patients With Liver } \\
\text { Cancer }\end{array}$ & Rak wątrobowokomórkowy & PBT vs EBRT & Przeżycie całkowite \\
\hline NCTo1230866 & $\begin{array}{l}\text { Study of Hypo- } \\
\text { fractionated Proton } \\
\text { Radiation for Low } \\
\text { Risk Prostate Cancer }\end{array}$ & Rakprostaty & $\begin{array}{c}\text { PBT (5x7,6Gy } \\
\text { RBE) vs PBT } \\
\text { (44X1,8Gy } \\
\text { RBE) }\end{array}$ & $\begin{array}{c}\text { Okres bez } \\
\text { niepowodzenia }\end{array}$ \\
\hline
\end{tabular}




\begin{tabular}{|c|c|c|c|c|}
\hline NCTo1963429 & $\begin{array}{l}\text { Comparison Between } \\
\text { Radiofrequency } \\
\text { Ablation and } \\
\text { Hypofractionated } \\
\text { Proton Beam } \\
\text { Radiation for } \\
\text { Recurrent/Residual } \\
\text { HCC }\end{array}$ & Rak wątrobowokomórkowy & PBTvs RFA & $\begin{array}{l}\text { Przeżycie bez } \\
\text { progresji }\end{array}$ \\
\hline NCTo2640924 & $\begin{array}{l}\text { Proton } \\
\text { Radiotherapy Versus } \\
\text { Radiofrequency } \\
\text { Ablation for Patients } \\
\text { With Medium or } \\
\text { Large Hepatocellular } \\
\text { Carcinoma } \\
\end{array}$ & Rak wątrobowokomórkowy & PBT vs RFA & Kontrola Miejscowa \\
\hline NCTo1182779 & $\begin{array}{l}\text { Trial of Proton Versus } \\
\text { Carbon Ion Radiation } \\
\text { Therapy in Patients } \\
\text { With Chordoma of the } \\
\text { Skull Base (HIT-1) }\end{array}$ & Struniak & PBT vs Carbon & $\begin{array}{l}\text { Przeżycie bez } \\
\text { progresji }\end{array}$ \\
\hline NCTo3285815 & $\begin{array}{l}\text { Prostate Cancer } \\
\text { - Localized } \\
\text { Adenocarcinoma } \\
\text { Proton Therapy }\end{array}$ & Rakprostaty & $\begin{array}{c}\text { PBT (20x3 } \\
\text { CGE) vs PBT } \\
\text { (10x 4,7 CGE) }\end{array}$ & $\begin{array}{l}\text { Przeżycie bez wznowy } \\
\text { biochemicznej }\end{array}$ \\
\hline NCTo1811394 & $\begin{array}{l}\text { Ion Irradiation of } \\
\text { Sacrococcygeal } \\
\text { Chordoma (ISAC) }\end{array}$ & Struniak & PBT vs Carbon & $\begin{array}{c}\text { Toksyczność wczesna } \\
\text { i późna }\end{array}$ \\
\hline NCTo2731001 & $\begin{array}{l}\text { Proton Therapy to } \\
\text { Reduce Acute Normal } \\
\text { Tissue Toxicity in } \\
\text { Locally Advanced } \\
\text { Non-small-cell Lung } \\
\text { Cancer (PRONTOX) }\end{array}$ & $\begin{array}{c}\text { Niedrobnokomórkowy rak } \\
\text { płuca }\end{array}$ & $\begin{array}{l}\text { PBT vs EBRT } \\
\text { (RCTH) }\end{array}$ & Toksyczność wczesna \\
\hline NCTo3180502 & $\begin{array}{l}\text { Proton Beam or } \\
\text { Intensity-Modulated } \\
\text { Radiation Therapy } \\
\text { in Preserving Brain } \\
\text { Function in Patients } \\
\text { With IDH Mutant } \\
\text { Grade II or III Glioma }\end{array}$ & Glejak złośliwy & PBT vs EBRT & Funkcjekognitywne \\
\hline NCTo3132532 & $\begin{array}{l}\text { Phase II Trial } \\
\text { of Standard } \\
\text { Chemotherapy } \\
\text { (Carboplatin \& } \\
\text { Paclitaxel) +Various } \\
\text { Proton Beam Therapy } \\
\text { (PBT) Doses }\end{array}$ & $\begin{array}{c}\text { Niedrobnokomórkowy rak } \\
\text { płuca }\end{array}$ & $\begin{array}{l}\text { PBT 6oGy vs } \\
\text { PBT } 66 \text { Gy vs } \\
\text { PBT } 72 \text { Gy }\end{array}$ & $\begin{array}{l}\text { Przeżycie bez } \\
\text { progresji }\end{array}$ \\
\hline
\end{tabular}




\begin{tabular}{|c|c|c|c|c|}
\hline NCT01182753 & $\begin{array}{l}\text { Trial of Proton Versus } \\
\text { Carbon Ion Radiation } \\
\text { Therapy in Patients } \\
\text { With Low and Inter- } \\
\text { mediate Grade } \\
\text { Chondrosarcoma } \\
\text { of the Skull Base } \\
\text { (CSP12C) }\end{array}$ & Chrzęstniakomięsak & PBT vs Carbon & $\begin{array}{l}\text { Przeżycie bez } \\
\text { progresji }\end{array}$ \\
\hline NCT01893307 & $\begin{array}{l}\text { Randomized Trial of } \\
\text { Intensity-Modulated } \\
\text { Proton Beam } \\
\text { Therapy (IMPT) } \\
\text { Versus Intensity- } \\
\text { Modulated Photon } \\
\text { Therapy (IMRT) } \\
\text { for the Treatment } \\
\text { of Oropharyngeal } \\
\text { Cancer of the Head } \\
\text { and Neck }\end{array}$ & Rak gardła środkowego & PBT vs EBRT & Toksycznośćwczesna \\
\hline NCTo2179086 & $\begin{array}{l}\text { Dose-Escalated } \\
\text { Photon IMRT } \\
\text { or Proton Beam } \\
\text { Radiation Therapy } \\
\text { Versus Standard-Dose } \\
\text { Radiation Therapy } \\
\text { and Temozolomide } \\
\text { in Treating } \\
\text { Patients With } \\
\text { Newly Diagnosed } \\
\text { Glioblastoma }\end{array}$ & Glejak złośliwy & PBT vs EBRT & Przeżycie całkowite \\
\hline NCTo1617161 & $\begin{array}{l}\text { Proton Therapy vs. } \\
\text { IMRT for Low or } \\
\text { Intermediate Risk } \\
\text { Prostate Cancer } \\
\text { (PARTIQoL) }\end{array}$ & & PBT vs EBRT & $\begin{array}{c}\text { Toksyczność wczesna } \\
\text { i późna }\end{array}$ \\
\hline NCTo3829033 & $\begin{array}{l}\text { Photon Therapy } \\
\text { Versus Proton } \\
\text { Therapy in Early } \\
\text { Tonsil Cancer. } \\
\text { (ARTSCAN V }\end{array}$ & Rak gardła środkowego & PBT vs EBRT & $\begin{array}{c}\text { Toksyczność wczesna } \\
\text { i późna }\end{array}$ \\
\hline NCTo1993810 & $\begin{array}{l}\text { Comparing Photon } \\
\text { Therapy To Proton } \\
\text { Therapy To Treat } \\
\text { Patients With Lung } \\
\text { Cancer(RTOG) }\end{array}$ & $\begin{array}{c}\text { Niedrobnokomórkowy rak } \\
\text { płuca }\end{array}$ & $\begin{array}{l}\text { PBT vs EBRT } \\
\text { CRTH }\end{array}$ & $\begin{array}{l}\text { Przeżycie całkowite, } \\
\text { Toksyczność sercowo- } \\
\text { naczyniowa }\end{array}$ \\
\hline NCTo2923570 & $\begin{array}{l}\text { Study of Proton } \\
\text { Versus Photon Beam } \\
\text { Radiotherapy in the } \\
\text { Treatment of Head } \\
\text { and Neck Cancer }\end{array}$ & $\begin{array}{l}\text { Jednostronny rak regionu } \\
\text { głowy i szyi (ślinianka, skóra, } \\
\text { czerniak) }\end{array}$ & PBT vs EBRT & Toksyczność wczesna \\
\hline
\end{tabular}




\begin{tabular}{|c|c|c|c|c|}
\hline NCTo316446o & $\begin{array}{l}\text { Stereotactic Body } \\
\text { Radiation Therapy or } \\
\text { Intensity Modulated } \\
\text { Radiation/Proton } \\
\text { Therapy in Treating } \\
\text { Patients With } \\
\text { Recurrent Head and } \\
\text { Neck Cancer }\end{array}$ & $\begin{array}{c}\text { Nawrotowy rak region głowy } \\
\text { i szyi }\end{array}$ & $\begin{array}{l}\text { PBT vs EBRT vs } \\
\text { SBRT }\end{array}$ & $\begin{array}{c}\text { Toksycznośćc wczesna } \\
\text { i późna }\end{array}$ \\
\hline NCTo2783690 & $\begin{array}{l}\text { A Trial of } 15 \text { Fraction } \\
\text { vs } 25 \text { Fraction Pencil } \\
\text { Beam Scanning } \\
\text { Proton Radiotherapy } \\
\text { After Mastectomy in } \\
\text { Patients Requiring } \\
\text { Regional Nodal } \\
\text { Irradiation }\end{array}$ & Rak piersi & $\begin{array}{c}\text { PBT } 50 G y / 25 f x \\
\text { vs PBT } \\
40 G y / 5 f x\end{array}$ & $\begin{array}{c}\text { Toksyczność wczesna } \\
\text { i późna }\end{array}$ \\
\hline
\end{tabular}

\section{Czy to najlepsza droga na wykazanie korzyści z nowych form radioterapii?}

NiewielkaliczbaRCTs wynika z wielu przyczyn. Przede wszystkim potencjalne wskazania do protonoterapii w większości dotyczącą rzadkich schorzeń, takich jak nowotwory wieku dziecięcego czy mięsaki lokalizacji okołooponowej. Nawet w prawie 40-milionowej populacji Polski liczba nowotworów wieku dziecięcego mogących odnieść korzyść z radioterapii cząsteczkowej została oszacowana przez ekspertów na ok. 150 przypadków rocznie [3]. Uwzględniając dodatkowo ograniczoną liczbę ośrodków dysponujących odpowiednią aparaturą, konstrukcja RCTs z grupami pacjentów o odpowiedniej liczebności jest wyjątkowo trudna.

Co więcej, w wielu sytuacjach przeprowadzenie RCTs jest klinicznie niemożliwe, np. w części przypadków powtórnego napromieniania nowotworów głowy i szyi. Radioterapia cząsteczkowa dzięki swojemu unikalnemu rozkładowi dawki jest jedyną potencjalną opcją terapeutyczną wtedy, gdy stosując klasyczną radioterapię fotonową (czyli ewentualne ramiękontrolne) przekraczamy dopuszczalne dawki kumulacyjne, oznaczające nieakceptowalne ryzyko toksyczności w narządach krytycznych.

Niektórzy autorzy podnoszą również aspekt etyczny, gdy proponujemy pacjentom randomizację, wiedząc o wyraźnej korzyści dozymetrycznej jednej z metod [4]. Jest to istotne zwłaszcza w przypadku leczenia dzieci.

Istnieje wątpliwość czy RCTs są najlepszą drogą do ewaluacji metod leczenia takich jak radioterapia [5]. Przyklasycznym podejściu do badań randomizowanych z interwencją - polegającą na podaniu nowego leku,leku w innej dawce lub dodaniu leku - punktem końcowym zazwyczaj jest poprawawynikuleczenia. W przypadku wprowadzania nowych technologii w radioterapii (takich jak techniki dynamiczne, radioterapia sterowana obrazem, czy wreszcie radioterapia cząsteczkowa) najczęstszym punktem końcowym jest poprawa jakości leczenia. Ocena wyników klinicznych przez pryzmat jakości leczenia jest możliwa, trzeba się jednak liczyć z niską czułością i specyficznością [6].

Dodatkowo, w przypadku szybko rozwijających się technologii ijednocześnie długiej rekrutacji, a następnie obserwacji chorych, wyniki obciążone są błędnymi założeniami metodologicznymi a priori i skutkują wynikami nieadekwatnymi do panujących realiów technologicznych w momencie publikacji. Istnieje także ryzyko uzyskania niewiarygodnych wyników wynikające z różnicy w doświadczeniu personelu posługującego się daną technologią w poszczególnych ośrodkach. Szeroko omawiane randomizowane badanie porównujące radioterapię klasyczną i protonową w raku płuca [7] jest przykładem na nieuniknioną krzywą uczenia, nawet w tak prestiżowym ośrodku jak MD Anderson Cancer Center (Houston, USA). Choć całościowy wynik badania nie wykazuje różnic w obu metodach leczenia, to jednak analizując jedynie chorychwłączanych od połowy okresu rekrutacji, wyniki dla protonoterapii stają się wyraźnie lepsze. Wynika to z wprowadzenia innych technik obrazowania w protonoterapii (IGRT - PBT), uwzględnienia ruchomości guza i stosowania tzw. „robustplanning” (ang. „pewne planowanie”). 


\section{Czy zawsze w medycynie używano RCTs?}

Warto ponadto zauważyć, że wdrażaniu nowych technologii w radioterapii rzadko towarzyszą badania randomizowane: wprowadzenie symulatorów, planowania opartego na tomografii komputerowej (ang. computedtomography, CT), czy radioterapii megawoltowej nie zostało poprzedzone takimi badaniami [5]. Nawet przejściu z technik statycznych na techniki dynamiczne w klasycznej radioterapii fotonowej towarzyszyła znikoma liczba RCTs. Wprowadzenie wielu innych procedur czy leków - np. penicyliny, insuliny, imatynibu w leczeniu białaczki czy stosowanie defibrylacji w migotaniu komór - również oparto o historyczne badania niższej mocy dowodowej niż RCTs[8]. Nieracjonalność uporczywego wymagania badań randomizowanych określa się żartobliwie „paradygmatem spadochronu”, którego skuteczności również nie wspierają takie dane [9].

\section{Jeśli nie RCTs to co?}

Mając to na uwadze, Europejska Grupa Radioterapii Cząsteczkowej (EPTN - EuropeanParticleTherapy Network) przy ESTRO (Europejskie Towarzystwo Radioterapii Onkologicznej), zaleca zdecydowaną zmianę podejścia do projektowania badań naukowych w dziedzinie radioterapii cząsteczkowej [10]. Zaleca się ograniczenie RCTs do sytuacji klinicznej, w której zakładamy ekwiwalentną toksyczność obu metod, przy eskalacji dawki w ramieniu cząsteczkowym tak, aby wykazać zysk terapeutyczny (w kontroli choroby lub przeżyciach). Jest to zdecydowana zmian w stosunku do obecnie prowadzonych badań.

We wszystkich innych przypadkach, gdy w obu ramionach stosujemy równoważne dawki, zakładając jedynie zmniejszenie toksyczności - za wystarczające uznaje się wyciąganie wniosków klinicznych w oparciu o dozymetryczne porównania planów leczenia. Pominięcie takich danych i uznawanie ich za niewystarczający dowód, zaprzeczałoby podstawowym dogmatom radioterapii.

Zaawansowanym matematycznie rozwinięciem powyższej koncepcji, zdobywającym powszechne uznanie na świecie, jest modelowanie obniżenie ryzyka wystąpienia toksyczności, czyli tzw. Model-BasedApproach (z ang. podejście w oparciu o model). [11]. Jest to koncepcja rozwinięta w Holandii, opierająca się na wyznaczeniu krzywych prawdopodobieństwa wystąpienia określonego odczynu popromiennego (NTCP) a następnie oszacowaniu zysku w postaci obniżenia tegoż ryzyka ( $\triangle \mathrm{NTCP}$ ) porównując plan protonowy z najlepszym planem fotonowym. Po spełnieniu minimalnych kryteriów zysku, pacjent zostaje zakwalifikowany do leczenia radioterapią protonową. Pierwsze doświadczenie Szpitala Uniwersyteckiego UMCG w Groningen w Holandiiwskazują, że prawie 30\% pacjentów z nowotworami głowy i szyi odnosi korzyść i kwalifikuje się do protonoterapii[12]. Metoda ta uznana jest też przez lokalnego płatnika jako podstawa do refundacji [13]. Podobny model refundacyjny, w oparciu o ekspercką analizę planów leczenia, funkcjonuje np. w Austrii.

Takie podejście wydaje się być optymalne przy kwalifikacji pacjentów do leczenia (oraz przy rekrutacji do potencjalnych badań klinicznych). Kluczowy jest wybór konkretnej sytuacji klinicznej i odpowiedniego pacjenta, poprzedzony analizą możliwych rozkładów dawek z różnych metod leczenia, zamiast rozpatrywania danej grupy rozpoznań jako całości.

\section{Podsumowanie}

Oczywistym jest, że wprowadzanie kosztownych technologii w medycynie wymaga uzasadnienia w dowodach naukowych. Otwartym pytaniem jest, czy randomizowane badania kliniczne z grupą kontrolną są najlepszym sposobem ich pozyskania. Szczególnego zastanowienia wymaga również podejście do ich konstruowania i skupienie się na poprawie wyników leczenia, a nie tylko obniżaniu toksyczności. W innych sytuacjach wystarczających surogatem mogą być modele matematyczne.

\section{Deklaracje}

Praca powstała przy wsparciu grantu naukowego Wielkopolskiego Centrum Onkologii w Poznaniu nr 14/2018 (012). 


\section{Bibliografia}

[1] Strona internetowa PTCOG: https://ptcog.ch, dostęp 25.05.2019

[2] Timmermann B.Clinical Rationale for Proton Beam Radiotherapy, "Particle Therapy ESTRO Course", Groningen, Holandia, 18-22.03.2019

[3] Malicki J et al. Strategia Rozwoju Protonoterapii w Polsce, Warszawa 2018

[4] Goitein M, Cox JD.Should randomized clinical trials be required for proton radiotherapy?J Clin Oncol. 2008;26(2):175-6.

[5] Bentzen SM.Randomized controlled trials in health technology assessment: Overkill or overdue? Radiotherapy and oncology, 2008,86(2):142-147

[6] Lilford RJ, Brown CA, Nicholl J. Use of process measures to monitor the quality of clinical practice. BMJ 2007; 335:648-650. [PubMed: 17901516]

[7] Liao Z, Lee JJ, Komaki R, Gomez DR, O’Reilly MS, Fossella FVet al. Bayesian Adaptive Randomization Trial of Passive Scattering Proton Therapy and Intensity-Modulated Photon Radiotherapy for Locally Advanced Non-Small-CellLung Cancer, J Clin Oncol 2018; 36(18):1813:1822

[8] Rawlins M.De testimonio: on the evidence for decisions about the use of therapeutic interventions, Lancet 2008;372(9656):2152-61

[9] Smith GC, Pell JP. Parachute use to prevent death and major trauma related to gravitational challenge: systematic review of randomised controlled trials. BMJ. 2003; 327:1459-1461.

[10] EPTN Meeting, ESTRO Forum 2018, Barcelona

[11] Langendijk JA, Lambin P, De Ruysscher D, Widder J, Bos M, Verheij M.Selection of patients for radiotherapy with protons aiming at reduction of side effects: the model-based approach.Radiother Oncol. 2013;107(3):267-73.

[12] Rwigema JM, Langendijk JA, Paul van der Laan H, Lukens JN, Swisher-McClure SD, Lin A.A ModelBased Approach to Predict Short-Term Toxicity Benefits With Proton Therapy for Oropharyngeal Cancer, Int J Radiat Oncol Biol Phys. 2019;104(3):553-562

[13] LandelijkIndicatie Protocol ProtonenTherapie, Holandia, 2017 